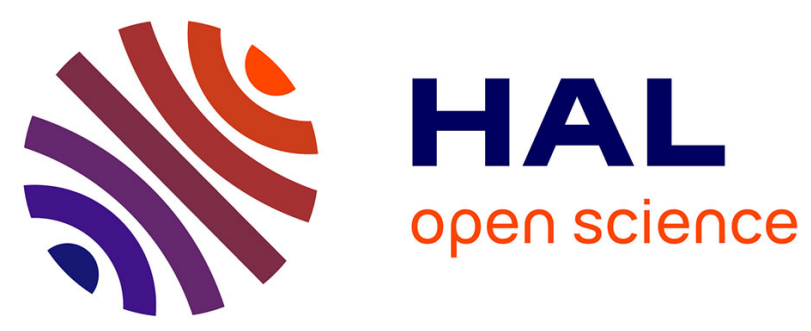

\title{
Ethanolamine Produced from Oleoylethanolamide Degradation Contributes to Acetylcholine/Dopamine Balance Modulating Eating Behavior
}

\author{
Ilario Mennella, Gaëlle Boudry, David Val-Laillet
}

\section{- To cite this version:}

Ilario Mennella, Gaëlle Boudry, David Val-Laillet. Ethanolamine Produced from Oleoylethanolamide Degradation Contributes to Acetylcholine/Dopamine Balance Modulating Eating Behavior. Journal of Nutrition, 2019, 149 (3), pp.362-365. 10.1093/jn/nxy281 . hal-02050393

HAL Id: hal-02050393

https://hal-univ-rennes1.archives-ouvertes.fr/hal-02050393

Submitted on 10 Sep 2019

HAL is a multi-disciplinary open access archive for the deposit and dissemination of scientific research documents, whether they are published or not. The documents may come from teaching and research institutions in France or abroad, or from public or private research centers.
L'archive ouverte pluridisciplinaire HAL, est destinée au dépôt et à la diffusion de documents scientifiques de niveau recherche, publiés ou non, émanant des établissements d'enseignement et de recherche français ou étrangers, des laboratoires publics ou privés. 
Ethanolamine produced from oleoylethanolamide degradation contributes to

acetylcholine/dopamine balance modulating eating behavior ${ }^{1,2,3,4}$

Ilario Mennella ${ }^{5,6}$, Gaëlle Boudry ${ }^{5}$, David Val-Laillet ${ }^{5}$

${ }^{5}$ Authors affiliation: INRA, INSERM, Univ Rennes, Nutrition Metabolisms and Cancer, NuMeCan, Rennes, St Gilles, France

${ }^{6}$ Corresponding author: Mailing address: Ilario Mennella, INRA NuMeCan, 16 Le Clos, 35590, Saint-Gilles, France. Phone: +33 223485652, fax: +33 223485080, e-mail:

ilariomennella@gmail.com

Names for PubMed indexing: Mennella I, Boudry G, Val-Laillet D

Word count: 1952

Number of figures: 1

Number of tables: 0

Supplementary data submitted: Supplemental Table 1

Running title: Ethanolamine in acetylcholine/dopamine balance

Keywords: dopaminergic system, N-acetylethanolamines, fatty acid amide hydrolase, gamma aminobutyric acid, endocannabinoids, neurotransmitters, neurons, neuromodulator

\footnotetext{
${ }^{1}$ List of abbreviations: acetylcholine (ACh); dopamine (DA); Oleoylethanolamide (OEA); N-acetylethanolamines (NAEs); ethanolamine (EA); nucleus accumbens (NAc); gamma aminobutyric acid (GABA); proliferator-activated receptor- $\alpha$ (PPAR- $\alpha)$

${ }^{2}$ Financial support: this publication has been written with the support of the AgreenSkills + fellowship programme which has received funding from the EU's Seventh Framework Programme under grant agreement $N^{\circ}$ FP7- 609398 (099/2017).

${ }^{3}$ Conflict of Interest and Funding Disclosure: Dr. Mennella reports grants from Brittany Region (SAD program, Stratégie d'Attractivité Durable), University Bretagne Loire, and from AgreenSkills+ during the conduct of the study. Gaëlle Boudry and David Val-Laillet declare no potential conflict of interest. The funding source had no involvement in decisions related to the research and publication of results.
} 
1 Oleoylethanolamide (OEA) is a well-recognized anorectic compound (1). Recent investigations

2 pointed out that, when administrated at a dose of $10 \mathrm{mg} / \mathrm{kg}$, it affects food reward by influencing the

3 acetylcholine (ACh)/dopamine (DA) balance in the cholinergic system (1). Recent published data

4 support the effect of OEA on both the homeostatic and non-homeostatic regulation of food intake

5 through the activation of proliferator-activated receptor- $\alpha$ (PPAR- $\alpha)$ in the small intestine, which

6 mediates satiety signals to the brain via the afferent vagal fibers (2).

7 Mammals have the enzymes to synthetize and degrade $\mathrm{N}$-acetylethanolamines (NAEs), including

8 OEA. NAEs are bios ynthesiz ed "on -demand" from their pr ecu rsors N-acylated ethanolamine

9 phospholipids, through three different enzymatic pathways (3). The absolute concentration of NAEs

10 in tissues is very low, in the order of a few nmol/g of tissue, the highest concentration being present

11 in the brain and intestine (3).

12 NAEs, including OEA, can also be provided by certain foods, oatmeal, nuts, and cocoa powder 13 being the major food sources, but the amount per gram of OEA found in these foods is very low $(<2$

$14 \mu \mathrm{g} / \mathrm{g}$ ) (4) compared to the amount used in clinical trials. OEA can also be synthetized upon

15 ingestion of precursor-containing foods, such as olive oil. For example, the intake of a meal

16 containing a high amount of oleic acid increased plasma concentration of OEA in rats and humans

$17(5,6)$ reducing the following energy intakes in humans $(6$, for a summary of human studies

18 addressing the role of OEA on eating behavior see supplemental table1).

19 NAEs hydrolysis is catalyzed by the fatty acid amide hydrolase that has a strong activity in the 20 intestine, liver, brain, and at the blood-brain barrier level (7), resulting in the production of fatty 21 acids and ethanolamine (EA). After OEA is orally or intragastrically administrated in relatively 22 abundant doses, i.e. $10 \mathrm{mg} / \mathrm{kg}$, it is likely that following its degradation, a peak in oleate and EA, occurs in several organs. The effect of oleic acid on the gut-brain-axis has been extensively investigated, whereas EA received scarce attention. One study (8) tested the effect of oral EA $(1.88 \mathrm{mg} / \mathrm{kg}$, the equivalent amount released by $10 \mathrm{mg} / \mathrm{kg}$ of OEA) and found no effect on food intake compared to a control group, in rats. However, in this study only food intake and no other 
aspects of eating behavior, such as food preferences for high sugar/fat foods that may also be influenced by the activation of brain areas related to food reward, were investigated. On the contrary, there are scattered evidences from old and new recent researches, which underline the influence of EA on the cholinergic system.

Here, we briefly describe OEA and EA effects on the cholinergic system, suggesting that EA contributes to the overall balance between DA and ACh after OEA administration $(9,10)$.

\section{The cholinergic system regulates food reward by interacting with the dopaminergic system}

The cholinergic system modulates various brain functions through the release of the Ach (11). This occurs as a result of depolarization of the axonal termination that induces

a rise in the cytosolic $\mathrm{Ca}^{2+}$ concentration and the fusion between the axoplasmic membrane and the vesicles containing $\mathrm{ACh}$.

Projection neurons constitute the main brain structure of the cholinergic system that originates mainly in subcortical regions, such as the basal forebrain, and extends into many brain regions, including cortical areas and the hippocampus. Interneurons with cholinergic activity were also identified in specific target areas of mesolimbic system, such as the nucleus accumbens (NAc) (11), which are involved in pleasure and motivation, contributing to the hedonic dimension of eating.

In the regulation of eating behavior, the cholinergic system constantly interacts with, and regulates the activity of one of the main neurotransmitters involved in reward, DA (12). DA is synthesized by dopaminergic neurons in the midbrain (i.e. ventral tegmental area and substantia nigra). The dopaminergic mesolimbic pathway is a neuronal circuit that is activated in order to translate motivation into action in a variety of behaviors, including eating (12).

In human lean subjects, food cues stimulate DA release in the dorsal striatum (12) and during eating, DA response is positively correlated with the pleasantness of the food. These evidences indicate that, in lean subjects, DA may be considered as a biomarker of the hedonic value of foods.

Conversely, in obese subjects, responses to food cues and food ingestion stimuli are blunted (12).

2 The dopaminergic and the cholinergic systems have a similar anatomical connectivity with 
53 numerous functional neuronal endings, such as in the NAc. Here, cholinergic interneurons, together

54 with dopaminergic projections of the ventral tegmental area, modulate the activity of gamma

55 aminobutyric acid (GABA) projections neurons (12). In the NAc, ACh/DA fluctuations modulate eating behavior. For example, when rats are exposed to an adverse conditioned stimulus, there is a concomitant ACh increase and DA decrease. In addition, fasted mice in a free feeding state stop eating when the $\mathrm{ACh} / \mathrm{DA}$ ratio begins to increase (12).

\section{OEA influences cholinergic-mediated food-reward regulation}

Some investigations also suggested that OEA influences the food-reward system by modulating DA release. High-fat-diet chronic consumption in mice produces a significant reduction in intestinal OEA synthesis, but not in other tissues, which is concomitant with a reduction of DA in the brain. In high-fat-diet-fed mice, infusion of OEA $(10 \mathrm{mg} / \mathrm{kg})$ solution $25 \mathrm{~min}$ before intragastric lipid emulsion infusion restored DA release. No difference was found in DA increase in response to the calories content of the emulsion. In low-fat-diet-fed mice, OEA influenced the release of DA when stimulated by intragastric infusion of a low-calorie emulsion. In addition, in low-fat-diet-fed mice, the infusion of OEA decreased the intake of both low-calorie and high-calorie emulsions. Finally, the authors demonstrated that these effects were abolished in sub-diaphragmatic bilaterally vagotomised and in PPAR- $\alpha$ knockout mice (1). These evidences indicate that OEA interacts with the mesolimbic system, probably via activation of the PPAR- $\alpha$ on vagal afferent nerves. In contrast, another investigation provides evidences that OEA can regulate DA release through central mechanisms as well. In rats, when injected in the lateral hypothalamus, OEA increased extracellular DA levels in NAc (9). The molecular mechanisms of OEA-DA interaction have not been fully clarified yet. 
79 The quantitative degradation of $10 \mathrm{mg}$ of OEA may produce $1.88 \mathrm{mg}$ of EA and this is particularly

80 interesting because it is a small molecule with a rather good ability to pass the blood-brain barrier

81 and influence the activity of diverse brain areas (13). Several pioneering studies demonstrated that

82 EA can be released from different brain regions following electrical or chemical depolarization (14).

83 A more recent in vitro study demonstrated that, when synaptosomes and synaptoneurosomes were incubated with EA, this was stored in intracellular compartments, and released by classical exocytosis following depolarization (15). The authors pointed out that the concentration of EA released was low compared to a classical neurotransmitter, but they did not exclude the possibility that a discrete receptor exists post-synaptically for EA (15). Although EA cannot be considered as a pure neurotransmitter, all in all, these studies support the role of EA as a neuromodulator, a molecule that is not directly excitatory or inhibitory, but that can sustain both activities depending on the site and the time frame of its release. Therefore, it is convincing that the EA released from the degradation of NAEs in the intestine or at the blood-brain barrier level may play a role in the brain. In fact, it is known that EA can modulate neurotransmitters. It was shown that EA stimulates the release of aspartic and glutamic acids in the anterior hippocampus of rabbits (16), and it is also known to inhibit the enzyme GABA aminotransferase with the consequence of reducing GABA breakdown and increasing its concentration in the brain (17).

Some investigations demonstrated that, similarly to OEA, EA could influence the cholinergic system. A first suggestion came from the neuronal cells' ability to use EA as a precursor of ACh. In chicken neuronal cultures, it was proved that EA is rapidly phosphorylated to phosphoethanolamine and converted to phosphatidylethanolamine that may also be methylated to phosphocholine (18). In vivo, intraventricular injections of ${ }^{3} \mathrm{H}$-EA showed that the rat brain has the capacity to synthetize free choline de novo by stepwise methylation of EA, phosphoethanolamine and phosphatidylethanolamine (19). In the human cell line neuroblastoma LA-N-2, it was demonstrated that the same pathway exists and that the choline thus produced is a source of de novo synthesis of ACh (20). In contrast, Ansell and Spanner (21) described that after injection of labeled EA in the 
105

106

107

ventricle side of the rat brain, labeled phosphatidylethanolamine was formed, but no labeled phosphatidylcholine was found. Similar results were obtained by Browning and Schulman (22) in slices of cerebral cortex of rats. They showed that labeled ACh was formed in the presence of labeled choline, whereas ACh was not labeled if choline was substituted with labeled EA, serine or methionine. Therefore it is accepted that, although the conversion of EA in ACh is possible, in vivo and in the presence of normal plasma choline levels, EA is not used for choline and ACh synthesis.

However, other investigations found that EA can increase ACh extracellular concentration in the brain by indirect mechanisms. In cultured explants of the medial septal nucleus from rat brains, EA enhances the ability to develop cholinergic neurons to utilize choline for the production of ACh (23). EA has been shown to increase extracellular levels of ACh in rat hippocampus slices during continuous infusion in a depolarizing $\mathrm{KCl}$ buffer. This increase was not mediated by a greater synthesis of ACh, but by a higher cellular release that would be stimulated by amino-alcohols such as EA (24). In a subsequent study, they suggested that the mechanism through which aminoalcohols facilitate ACh release in the hippocampus may involve the activation of calcium channels (25). Interestingly, this effect appears to be specific to cholinergic endings, since other neurotransmitters, such as norepinephrine and DA, were not affected. A similar result was obtained by Khairy et al. (10) who have shown that the application of EA on dorsal root ganglion (DRG) neurons cells, with a threshold of $10 \mathrm{nM}$, increases the amplitude and duration of the transport of $\mathrm{KCl}$-stimulated $\mathrm{Ca}^{2+}$ release. Furthermore, EA stimulated voltage-activated $\mathrm{K}^{+}$currents independently of the activation of $\mathrm{Ca}^{2+}$ channels. In another study, Liao et al. (17) in accordance Bostwick, also found that EA increased neurotransmitters release from brain synaptosomes, but they proposed different mechanisms of release. They demonstrated that synaptosomes incubated with EA, at a concentration from $0.31 \mathrm{mM}$ to $5 \mathrm{mM}$, increased their capability to release neurotransmitters, i.e. $[3 \mathrm{H}]-\mathrm{D}$-aspartic acid. They suggested that EA permeated into synaptic vesicles and increasing their filling capability. The enhanced capability of synaptic vesicles to load neurotransmitters explains how EA influence may regulate synaptic transmission. The 
131 concentrations used in the study were within physiological levels of EA in the brain, i.e. between $132 \quad 197-870 \mathrm{nmol} / \mathrm{g}(17)$.

133 Therefore, even if the mechanisms are still not clear, there are strong evidences to support that EA 134 influences neurotransmitters release in the brain. This is of great interest especially when the source 135 of EA is OEA, because this NAE has itself an action on the cholinergic/dopaminergic system. It is 136 also possible that there are differences in the overall effect on the brain between the administration 137 of pure EA, as investigated by Nielsen et al (8) and EA released following OEA degradation, since 138 this EA can keep acting on neurotransmitters previously stimulated by OEA.

139 In conclusion, these evidences support the hypothesis that OEA and its metabolite, EA, can interact 140 in the regulation of the overall $\mathrm{ACh} / \mathrm{DA}$ balance influencing brain areas involved in food-reward 141 (Figure 1). Taking into account this perspective, further studies should investigate the kinetic of EA 142 release following OEA administration and whether it can impact the cholinergic regulation of 143 dopamine.

145 Statement of authors' contributions to manuscript: IM, GB and DV wrote the article, IM 146 designed research and had primary responsibility for final content. All authors have read and 147 approved the final manuscript. 


\section{References}

1. Tellez LA, Medina S, Han W, Ferreira JG, Licona-Limón P, Ren X, et al. A Gut Lipid Messenger Links Excess Dietary Fat to Dopamine Deficiency. Science. 2013; 341:800-802.

2. Melis M, Pistis M. Targeting the interaction between fatty acid ethanolamides and nicotinic receptors: therapeutic perspectives. Pharmacological Research. 2014; 86:42-49.

3.Hansen HS, Diep TA. N-acylethanolamines, anandamide and food intake. Biochem Pharmacol. 2009; 78:553-60.

4.Laleh P, Yaser K, Abolfazl B, Shahriar A, Mohammad AJ, Nazila F, Alireza O.

Oleoylethanolamide increases the expression of PPAR-A and redu ces appe ti te and bod y

weight in obese people: A clinical trial. Appetite. 2018; 128:44-49.

5.Artmann A, Petersen G, Hellgren LI, Boberg J, Skonberg C, Nellemann C, Hansen SH, Hansen HS. Influence of dietary fatty acids on endocannabinoid and $\mathrm{N}$-acylethanolamine levels in rat brain, liver and small intestine. Biochim Biophys Acta. 2008; 1781:200-12.

6.Mennella I, Savarese M, Ferracane R, Sacchi R, Vitaglione P. Oleic acid content of a meal promotes oleoylethanolamide response and reduces subsequent energy intake in humans. Food \& function. 2015; 6:203-209.

7. Egertová M, Cravatt BF, Elphick MR. Fatty acid amide hydrolase expression in rat choroid plexus: possible role in regulation of the sleep-inducing action of oleamide. Neurosci Lett. $2000 ; 282: 13-6$.

8.Nielsen MJ, Petersen G, Astrup A, Hansen HS. Food intake is inhibited by oral oleoylethanolamide. J Lipid Res. 2004; 45:1027-9.

9. Sihag J, Jones PJH. Oleoylethanolamide: The role of a bioactive lipid amide in modulating eating behaviour. Obes Rev 2018 ; 19:178-197.

10. Khairy H, Adjei G, Allen-Redpath K, Scott RH. Action of ethanolamine on cultured sensory neurones from neonatal rats. Neuroscience Letters. 2010; 468:326-329. 
11. Picciotto MR, Higley MJ, Mineur YS. Acetylcholine as a neuromodulator: cholinergic signaling shapes nervous system function and behavior. Neuron. 2012; 76:116-29

12. Mark GP, Shabani S, Dobbs LK, Hansen ST. Cholinergic modulation of mesolimbic dopamine function and reward. Physiol Behav. 2011; 104:76-81.

13. Loscher W. Effect of 2-aminoethanol on the synthesis, binding, uptake and metabolism of GABA. Neuroscience Letters. 1983; 42:293-297.

14. Pershak H, Wolfensberger M, Do KO, Dunant Y, Cuenod M. Release of ethanolamine, but not serine or choline, in rat pontine nuclei on stimulation of afferents from the cortex, in vivo, J. Neurochem. 1986; 46:1338-1343.

15. Liao C, Nicholson RA. Depolarization-induced release of ethanolamine from brain synaptic preparations in vitro. Brain Res. 2005; 1060:170-8.

16. Buratta S, Hamberger A, Ryberg H, Nystrom B, Sandberg M, Mozzi M. Effect of serine and ethanolamine administration on phospholipidrelated compounds and neurotransmitter amino acids in the rabbit hippocampus. J. Neurochem. 1998; 71:2145-2150.

17. Liao C, Nicholson RA. Ethanolamine and related amino alcohols increase basal and evoked release of $[3 \mathrm{H}]-\mathrm{D}$-aspartic acid from synaptosomes by enhancing the filling of synaptic vesicles. Eur J Pharmacol. 2007; 566:103-12.

18. Massarelli AC, Dainous F, Hoffmann D, Mykita S, Freysz L, Dreyfus H, Massarelli R. Uptake of ethanolamine in neuronal and glial cell cultures. Neurochem Res. 1986; 11:29-36.

19. Andriamampandry C, Freysz L, Kanfer JN, Dreyfus H, Massarelli R. Conversion of ethanolamine, monomethylethanolamine and dimethylethanolamine to choline-containing compounds by neurons in culture and by the rat brain. Biochem J. 1989; 264:555-562.

20. Haidar NE, Carrara M, Andriamampandry C, Kanfer JN, Freysz L, Dreyfus H, Massarelli R. Incorporation of $[3 \mathrm{H}]$ ethanolamine into acetylcholine by a human cholinergic neuroblastoma clone. Neurochem Res. 1994; 19:9-13. 
21. Ansell GB, Spanner S. The metabolism of labelled ethanolamine in the brain of the rat in vivo. J. Neurochem. 1967; 14:873-885.

22. Browning ET, Shulman MP. [14C] Acetylcholine synthesis by cortex slices of rat brain. J Neurochem. 1968; 15:1391-1405.

23. Bostwick JR, Landers DW, Crawford G, Lau K, Appel SH. Purification and characterization of a central cholinergic enhancing factor from rat brain its identity as phosphoethanolamine. J Neurochem. 1989; 53:448-458.

24. Bostwick JR, Abbe R, Sun J, Appel SH. Amino alcohol modulation of hippocampal acetylcholine release. NeuroReport. 1992; 3:425-428.

25. Bostwick JR, Abbe R, Appel SH. Modulation of acetylcholine release in hippocampus by amino alcohols and Bay K 8644. Brain Res. 1993; 629:79-87. 


\section{Figure Legends}

Figure 1. Schematic representation of oleoylethanolamide (OEA) and ethanolamine (EA) effects on acetylcholine/dopamine (ACh/DA) balance. From intestine, OEA communicates via vagal afferent fiber with brain areas regulating DA release. OEA is then degraded by the enzyme fatty acid amide hydrolase in oleic acid and EA, which pass into the bloodstream and can in part penetrate the blood brain barrier. In the brain, EA acts as a neuromodulator being able to stimulate cholinergic neurons $\mathrm{ACh}$ release. $\mathrm{ACh} / \mathrm{DA}$ fluctuations modulate eating behavior. 


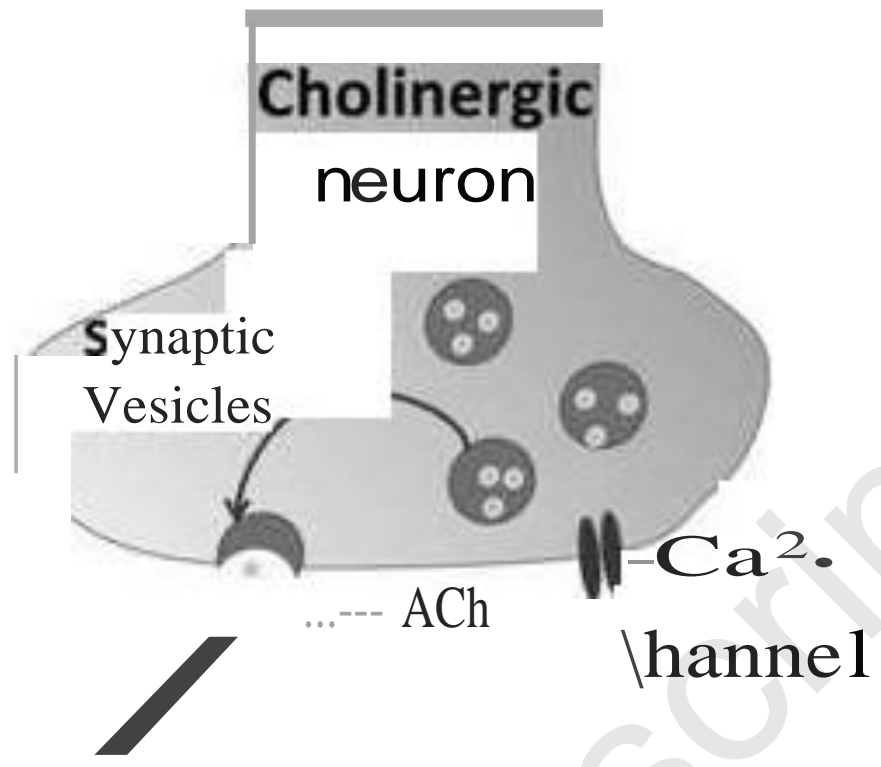

Ach/DA regulation Food reward control

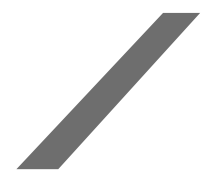

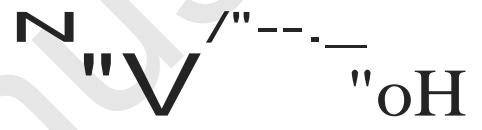

Ethanolamine

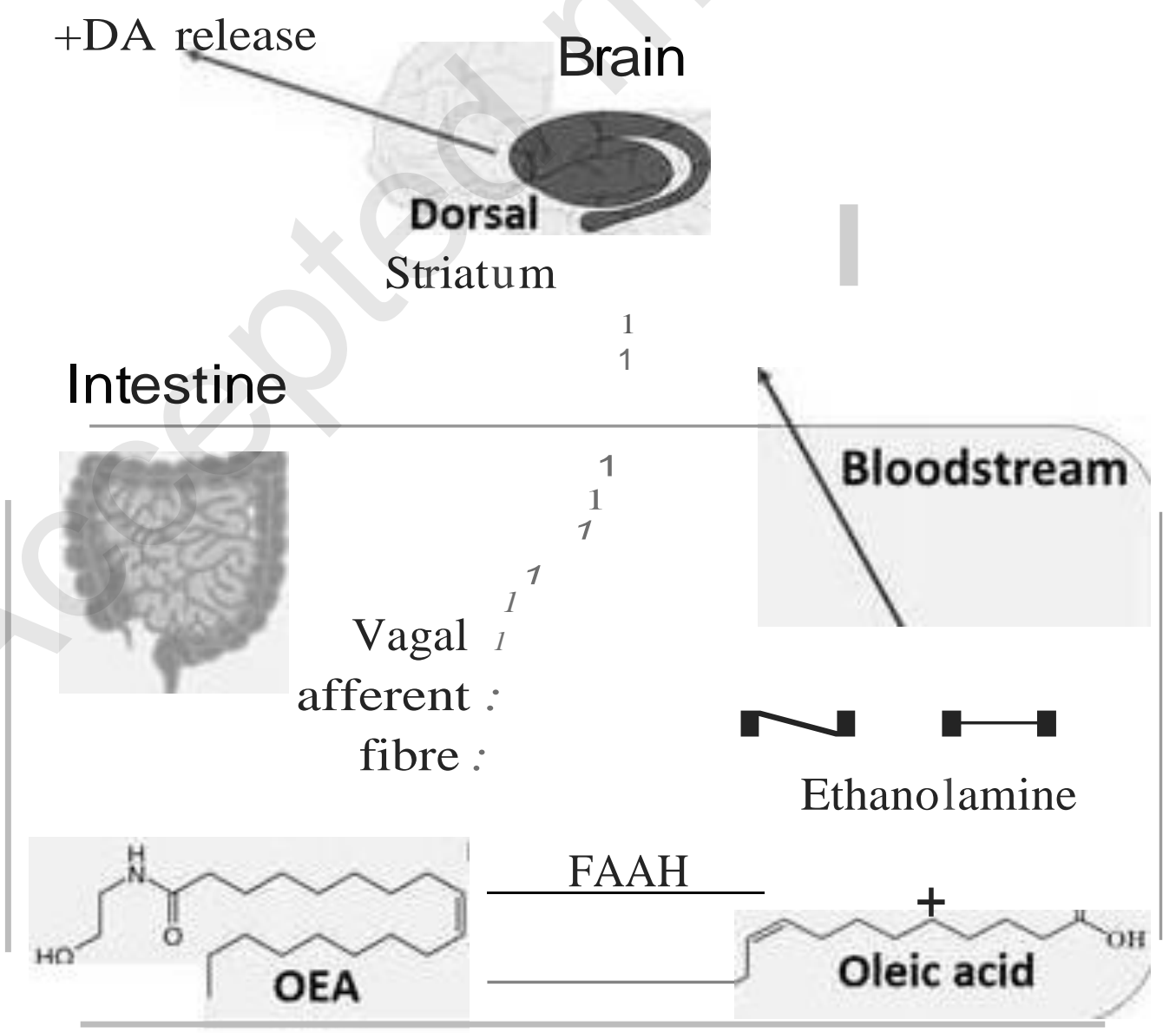

Figure 1 